University of Nebraska - Lincoln

DigitalCommons@University of Nebraska - Lincoln

Public Health Resources

Public Health Resources

2011

Substance use disorders in Iraq and Afghanistan veterans in VA healthcare, 2001-2010: Implications for screening, diagnosis and treatment

\author{
Karen H. Seal \\ University of California - San Francisco \\ Greg Cohen \\ San Francisco Veterans Affairs Medical Center \\ Angela Waldrop \\ University of California - San Francisco \\ Beth E. Cohen \\ University of California - San Francisco \\ Shira Maguen \\ University of California - San Francisco \\ See next page for additional authors
}

Follow this and additional works at: https://digitalcommons.unl.edu/publichealthresources

Part of the Public Health Commons

Seal, Karen H.; Cohen, Greg; Waldrop, Angela; Cohen, Beth E.; Maguen, Shira; and Ren, Li, "Substance use disorders in Iraq and Afghanistan veterans in VA healthcare, 2001-2010: Implications for screening, diagnosis and treatment" (2011). Public Health Resources. 198.

https://digitalcommons.unl.edu/publichealthresources/198

This Article is brought to you for free and open access by the Public Health Resources at DigitalCommons@University of Nebraska - Lincoln. It has been accepted for inclusion in Public Health Resources by an authorized administrator of DigitalCommons@University of Nebraska - Lincoln. 


\section{Authors}

Karen H. Seal, Greg Cohen, Angela Waldrop, Beth E. Cohen, Shira Maguen, and Li Ren 


\title{
Substance use disorders in Iraq and Afghanistan veterans in VA healthcare, 2001-2010: Implications for screening, diagnosis and treatment
}

\author{
Karen H. Seal ${ }^{\mathrm{a}, *}$, Greg Cohen ${ }^{\mathrm{b}}$, Angela Waldrop ${ }^{\mathrm{a}}$, Beth E. Cohen ${ }^{\mathrm{a}}$, Shira Maguen ${ }^{\mathrm{a}}$, Li Ren $^{\mathrm{b}}$ \\ a University of California, San Francisco and San Francisco Veterans Affairs Medical Center, 4150 Clement St., San Francisco, CA 94121, United States \\ b San Francisco Veterans Affairs Medical Center, 4150 Clement St., San Francisco, CA 94121, United States
}

\section{A R T I C L E I N F O}

\section{Article history:}

Received 18 June 2010

Received in revised form 24 November 2010

Accepted 27 November 2010

Available online 31 January 2011

\section{Keywords:}

Alcohol use disorders

Drug use disorders

Posttraumatic stress disorder

Comorbidity

Veterans

\begin{abstract}
A B S T R A C T
Background: The prevalence and correlates of alcohol use disorder (AUD) and drug use disorder (DUD) diagnoses in Iraq and Afghanistan veterans who are new users of Department of Veterans Affairs (VA) healthcare nationwide has not been evaluated.

Methods: VA administrative data were used in retrospective cross-sectional descriptive and multivariable analyses to determine the prevalence and independent correlates of AUD and DUD in 456,502 Iraq and Afghanistan veterans who were first-time users of VA healthcare between October 15, 2001 and September 30, 2009 and followed through January 1, 2010.

Results: Over 11\% received substance use disorder diagnoses: AUD, DUD or both; 10\% received AUD diagnoses, $5 \%$ received DUD diagnoses and $3 \%$ received both. Male sex, age $<25$ years, being never married or divorced, and proxies for greater combat exposure were independently associated with AUD and DUD diagnoses. Of those with AUD, DUD or both diagnoses, 55-75\% also received PTSD or depression diagnoses. AUD, DUD or both diagnoses were 3-4.5 times more likely in veterans with PTSD and depression $(p<0.001)$.

Conclusions: Post-deployment AUD and DUD diagnoses were more prevalent in subgroups of Iraq and Afghanistan veterans and were highly comorbid with PTSD and depression. Stigma and lack of universal screening may have reduced the number of DUD diagnoses reported. There is a need for improved screening and diagnosis of substance use disorders and increased availability of integrated treatments that simultaneously address AUD and DUD in the context of PTSD and other deployment-related mental health disorders.
\end{abstract}

Published by Elsevier Ireland Ltd.

\section{Introduction}

American troops have been deployed to Afghanistan and subsequently to Iraq for nearly a decade. Many soldiers have endured multiple tours of duty and most have experienced combat. Making the transition from warzone to home has been challenging, especially for veterans who have sustained physical injuries, as well as those who have developed mental health problems. Indeed, the prevalence of mental health disorders in veterans of Operation Enduring Freedom (OEF, principally Afghanistan) and Operation Iraqi Freedom (OIF, principally Iraq), particularly posttraumatic stress disorder (PTSD), continues to rise, a trend that has been highlighted in the scientific and popular media (Associated Press, 2008; Friedman, 2010; Milliken et al., 2007; Seal et al., 2009; Tanielian and

\footnotetext{
* Corresponding author at: San Francisco VA Medical Center, 4150 Clement Street, Box 111A-1, San Francisco, CA 94121, United States. Tel.: +1 415221 4810x4852; fax: +1 4153795573.

E-mail addresses: Karen.Seal@va.gov, Karen.Seal@ucsf.edu (K.H. Seal).
}

Jaycox, 2008). In contrast, far less is known about the prevalence and predictors of alcohol use disorders (AUD) and there is only one published report in the medical literature about non-alcohol drug use disorders (DUD) in OEF/OIF military personnel and veterans (Hawkins et al., 2010). Knowledge of the prevalence and correlates of substance use disorders may facilitate early detection and inform targeted interventions to prevent chronic drug and alcohol problems in this current generation of returning veterans.

Recent studies have examined alcohol use in samples of OEF/OIF military service personnel and veterans (Calhoun et al., 2008; Hawkins et al., 2010; Jacobson et al., 2008; McDevitt-Murphy et al., 2010; Santiago et al., 2010; Wilk et al., 2010). In over 48,000 military service personnel participating in the Millennium Cohort Study, Jacobson and colleagues found that National Guard and Reserve personnel were at increased risk for new-onset heavy weekly drinking, binge drinking, and alcohol-related problems, compared to active duty forces (Jacobson et al., 2008). In crosssectional studies of smaller samples of OEF/OIF veterans in VA healthcare undergoing screening, 22-40\% screened positive for high-risk drinking (Calhoun et al., 2008; Erbes et al., 2007; Hawkins 
et al., 2010; McDevitt-Murphy et al., 2010); 7\% of OEF/OIF veterans in a small sample screened positive for cocaine and marijuana use disorders (Hawkins et al., 2010). Thus, while a few studies suggest increased risk for problem drinking and drug use through population screening, to date, there are no national-level studies of the prevalence and correlates of AUD or DUD diagnoses for the entire $\mathrm{OEF} / \mathrm{OIF}$ veteran population enrolled in VA healthcare in the United States.

Among civilians, up to one-half of those with a substance use disorder (SUD), including alcohol and drug abuse and dependence, also have at least one other comorbid mental health disorder and conversely, about $15-40 \%$ of individuals with a mental disorder also abuse substances (Grant et al., 2004; Kessler et al., 1996; Regier et al., 1990). In a large national cohort of Vietnam veterans, $73 \%$ of male Vietnam veterans met diagnostic criteria for comorbid PTSD and a lifetime diagnosis of AUD (Kulka et al., 1990). Comorbid SUDs are particularly important to consider in OEF/OIF veterans because of the high rate of co-occurring mental health diagnoses in this population (Seal et al., 2007, 2009). Several studies in both veterans and civilians have supported the prevailing hypothesis that self-medication of mental health symptoms, particularly PTSD symptoms, drives comorbidity with SUD (Bremner et al., 1996; Breslau et al., 2003; Chilcoat and Breslau, 1998). Other evidence however, suggests that SUDs promote the onset of psychiatric disorders and still other data point to shared causal pathways that are genetic or environmental (Kessler, 2004). Of clinical importance, individuals with SUDs that co-occur with other mental disorders often have more severe symptoms, require specialized treatment, and have poorer treatment outcomes (Kessler et al., 1996; Ouimette et al., 1998b; Watkins et al., 2001). Nevertheless, there are no published data on AUD and DUD comorbidity patterns in OEF/OIF veterans that could be used to guide clinical care of these returning veterans.

The Department of Veterans Affairs (VA) healthcare system is the single largest provider of healthcare for OEF/OIF veterans with $565,024(48 \%)$ of the over one million returned combat veterans enrolled (Department of Veterans Affairs, 2010). This study aimed to determine the prevalence and correlates of AUD and DUD diagnoses, including comorbid mental health disorders, in $\mathrm{OEF} / \mathrm{OIF}$ veterans who were new users of VA healthcare. A better understanding of factors associated with AUD and DUD, including comorbidity patterns, in the large number of veterans returning from war may facilitate targeted screening, secondary prevention, and stimulate more research on integrated treatments for co-occurring substance use and other mental health disorders.

\section{Methods}

\subsection{Study population}

The study population was identified using the VA OEF/OIF Roster (see below). Our target population was the subgroup of OEF/OIF veterans who, after October 15, 2001, had their first clinical visit to a VA healthcare facility after military service separation through September 30, $2009(n=648,023)$. We excluded OEF/OIF veterans if they had received VA healthcare prior to the start of OEF in October $2001(n=88,594)$ because our focus was on mental health diagnoses in OEF/OIF veterans who entered VA healthcare after the start of the wars in Iraq and Afghanistan. We also excluded veterans who were killed in action $(n=2122)$ and who first entered VA healthcare 90 days prior to the study end date $(n=100,805)$, which might preclude sufficient time to receive diagnoses. Thus, our final study population consisted of 456,502 OEF/OIF veterans who were first-time users of VA healthcare services between October 15 , 2001 and September 30, 2009 and were followed for at least 90 days until the study end date of January 1,2010 . The study was approved by the Committee on Human Research, University of California, San Francisco and the Human Research Protection Program at the San Francisco VA Medical Center.

\subsection{Source of data}

The VA OEF/OIF Roster is a growing national database of veterans who have separated from OEF and/or OIF military service, have enrolled in VA healthcare, and who have had at least one clinical encounter at a VA facility nationwide. The OEF/OIF Roster includes basic sociodemographic and military service information on OEF/OIF veterans, but has limited race/ethnicity categorizations and lacks information on income and educational attainment, as well as detailed information about level and type of combat exposure. OEF/OIF Roster data through 9/30/09 were linked to VA clinical data contained in the VA National Patient Care Database (NPCD) through $1 / 1 / 10$. The VA electronic medical record has been used extensively for research (Ashton et al., 2003; Boyko et al., 2000) and includes the date of the clinic visit and associated diagnosis(es) designated using International Classification of Diseases, Ninth Revision Clinical Modification (ICD-9-CM) codes.

\subsection{Definition of study variables}

2.3.1. Dependent outcome variables. The primary binary dependent outcome variable was the presence or absence of AUD or DUD diagnoses, including both abuse and dependence. Administrative ICD-9 CM codes for AUD and DUD correspond to Diagnostic and Statistical Manual of Mental Disorders, Fourth Edition, Text Revision (DSM-IV-TR) classifications (Tables 1 and 2, footnotes; American Psychiatric Association, 2000). Tobacco use disorders were not included. We also excluded ICD$9 \mathrm{CM}$ codes for AUD or DUD diagnoses "in remission" because we were focused on current SUD diagnoses that coincided with deployment to Iraq and Afghanistan and we could not verify when "in remission" diagnoses initially occurred and subsequently remitted in relation to the current conflicts. For multivariable analyses, in order to create mutually exclusive categories, veterans were classified as having either AUD diagnoses only, DUD diagnoses only or both AUD and DUD diagnoses.

2.3.2. Independent descriptive and predictor variables. Sociodemographic characteristics (e.g. age, sex, race/ethnicity) and military service characteristics, such as component type [National Guard or Reserve (NG/R) versus active duty (AD)], branch of service (i.e., Army, Navy, Air Force, Marines), rank, and whether veterans had been deployed once or more than once were included to evaluate the potential association with AUD and DUD. We also examined four common military service-related mental health diagnoses that have been associated with combat exposure (Kulka et al., 1990): PTSD, depressive disorders, anxiety disorders and adjustment disorders as putative comorbid mental health conditions with AUD, DUD or both (Table 3 footnotes). We chose these particular mental health diagnoses because they represent the most prevalent mental health diagnoses among OEF/OIF veterans enrolled in VA healthcare (Seal et al., 2007).

\subsection{Statistical analyses}

Multivariable logistic regression was used to determine independent sociodemographic and military service characteristics associated with AUD, DUD, or both Odds ratios (OR) with 95\% confidence intervals (CI) were adjusted for sex, age, race/ethnicity, marital status, rank, branch of service and multiple deployments. Odds ratios less than one indicated a lower likelihood of association of an independent variable (e.g. Navy) with AUD and DUD than the reference group (e.g. Army) We calculated the OR for the reference group in comparison to another group by taking the reciprocal of the other group. For example, the reciprocal of OR $=.18$ (or $\mathrm{OR}=1 / .18$ or $\mathrm{OR}=5.56$ ) is the calculated $\mathrm{OR}$ (or likelihood) of $18-24$-year olds (reference group) relative to veterans ages 40-71 years of receiving an AUD diagnosis. CIs around the point estimate for the reference group were derived by taking the reciprocal of the CIs of the comparison group.

As in other studies (Jacobson et al., 2008; Seal et al., 2007, 2009), a significant interaction was found between age and component type in association with AUD and DUD diagnoses in that NG/R veterans compared to AD veterans had differing AUD and DUD outcomes based on veterans' ages. To faithfully represent this interaction and to simplify interpretation, multivariable models were stratified by NG/R versus $\mathrm{AD}$ military component type. Multivariable methods were used to examine the independent associations of PTSD, depression, anxiety and adjustment disorders as potential comorbid conditions with AUD, DUD and both after adjustment for sociodemographic and military service characteristics, primary care and menta health services utilization (to mitigate possible ascertainment bias), and for clustering by VA facility. Because of the extremely large dataset, we set our threshold for significance at a $p$-value of $<0.001$. All multivariable analyses were conducted using Stata software (version 10.0; StataCorp LP, 2009) and SAS software (version 9.1.3; SAS Institute Inc., 2004).

\section{Results}

\subsection{Prevalence of alcohol and drug use disorders in OEF/OIF veterans}

Of the 456,502 OEF/OIF veterans who used VA healthcare for the first time from October 15, 2001 through January 1, 2010, 12\% were female, the median age was 28 [intraquartile range $(I Q R)=24-38$ ], and $36 \%$ were members of non-white ethnic minority groups. Fortyone percent were veterans of NG/R service, the majority (60\%) had 
Table 1

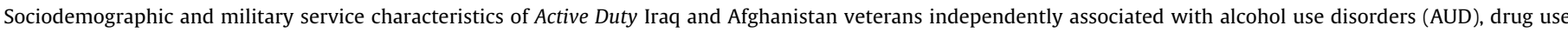
disorders (DUD) and both.

\begin{tabular}{|c|c|c|c|c|c|c|c|c|}
\hline \multirow[t]{3}{*}{ Characteristics } & \multicolumn{2}{|l|}{ Total } & \multicolumn{2}{|c|}{ AUD ${ }^{\mathrm{a}}$ only } & \multicolumn{2}{|c|}{ DUD ${ }^{\mathrm{a}}$ only } & \multicolumn{2}{|c|}{ AUD and DUD ${ }^{\mathrm{a}}$} \\
\hline & \multicolumn{2}{|c|}{$(n=270,246)$} & \multicolumn{2}{|c|}{$(n=18,779)$} & \multicolumn{2}{|c|}{$(n=4784)$} & \multicolumn{2}{|c|}{$(n=9315)$} \\
\hline & $n$ & $\% \mathrm{~b}$ & $\% \mathrm{~b}$ & $\mathrm{OR}^{\mathrm{c}}(95 \% \mathrm{CI})$ & $\% \mathrm{~b}$ & $\mathrm{OR}^{\mathrm{c}}(95 \% \mathrm{CI})$ & $\%$ & $\mathrm{OR}^{\mathrm{c}}(95 \% \mathrm{CI})$ \\
\hline \multicolumn{9}{|l|}{$\operatorname{Sex}^{\mathrm{d}}$} \\
\hline Female & 33,294 & 12.3 & 3.3 & 1 & 1.1 & 1 & 1.5 & 1 \\
\hline Male & 236,886 & 87.7 & 7.5 & $2.14(1.97,2.33)^{*}$ & 1.9 & $2.00(1.72,2.32)^{*}$ & 3.7 & $2.71(2.38,3.07)$ \\
\hline \multicolumn{9}{|l|}{ Race/ethnicity ${ }^{\mathrm{d}}$} \\
\hline White & 89,955 & 33.3 & 7.9 & 1 & 2.0 & 1 & 3.8 & 1 \\
\hline Black & 19,978 & 7.4 & 5.4 & $0.79(0.73,0.84)^{*}$ & 1.9 & $1.05(0.94,1.18)$ & 3.2 & $0.98(0.89,1.07)$ \\
\hline Hispanic & 29,513 & 10.9 & 8.0 & $0.99(0.94,1.04)$ & 1.5 & $0.71(0.64,0.79)^{*}$ & 3.1 & $0.82(0.76,0.88)$ \\
\hline Other ${ }^{\mathrm{e}}$ & 19,301 & 7.1 & 4.1 & $0.91(0.83,0.99)$ & 0.9 & $0.71(0.59,0.84)^{*}$ & 1.8 & $0.90(0.80,1.02)$ \\
\hline \multicolumn{9}{|l|}{ Age group (years) $)^{\mathrm{c}, \mathrm{d}}$} \\
\hline $18-24$ & 78,500 & 29.0 & 9.5 & 1 & 2.4 & 1 & 5.2 & 1 \\
\hline $25-29$ & 94,343 & 34.9 & 7.8 & $0.90(0.86,0.94)^{*}$ & 2.2 & $0.94(0.87,1.03)$ & 3.9 & $0.82(0.77,0.87)$ \\
\hline $30-39$ & 47,984 & 17.8 & 5.8 & $0.76(0.71,0.81)^{*}$ & 1.4 & $0.71(0.63,0.81)^{*}$ & 2.7 & $0.70(0.64,0.77)$ \\
\hline $40-71$ & 48,967 & 18.1 & 2.4 & $0.48(0.44,0.54)^{*}$ & 0.3 & $0.18(0.14,0.24)^{*}$ & 0.6 & $0.22(0.18,0.27)$ \\
\hline \multicolumn{9}{|l|}{ Marital status $^{\mathrm{d}}$} \\
\hline Married & 94,293 & 34.9 & 6.2 & 1 & 1.6 & 1 & 2.4 & 1 \\
\hline Never married & 91,979 & 34.0 & 9.6 & $1.34(1.27,1.40)^{*}$ & 2.2 & $0.98(0.90,1.08)$ & 5.0 & $1.67(1.55,1.79)$ \\
\hline Divorced/separated/widowed & 34,472 & 12.8 & 10.4 & $1.74(1.64,1.84)^{*}$ & 3.2 & $1.64(1.48,1.82)^{*}$ & 6.6 & $2.69(2.48,2.92)$ \\
\hline \multicolumn{9}{|l|}{ Rank } \\
\hline Enlisted & 253,178 & 93.7 & 7.3 & 1 & 7.3 & 1 & 3.7 & 1 \\
\hline Officer & 17,068 & 6.3 & 1.7 & $0.39(0.33,0.47)^{*}$ & 1.7 & $0.17(0.10,0.29)^{*}$ & 0.3 & $0.20(0.14,0.29)$ \\
\hline \multicolumn{9}{|l|}{ Branch $^{\mathrm{d}}$} \\
\hline Army & 122,709 & 45.4 & 7.9 & 1 & 7.8 & 1 & 4.5 & 1 \\
\hline Marines & 54,404 & 20.1 & 10.3 & $1.04(0.99,1.09)$ & 10.2 & $0.53(0.48,0.59)^{*}$ & 4.0 & $0.64(0.59,0.69)$ \\
\hline Navy & 51,982 & 19.2 & 4.5 & $0.59(0.55,0.63)^{*}$ & 4.4 & $0.51(0.44,0.58)^{*}$ & 2.2 & $0.49(0.44,0.54)$ \\
\hline Air Force & 40,873 & 15.1 & 2.9 & $0.54(0.49,0.58)^{*}$ & 2.9 & $0.62(0.53,0.71)^{*}$ & 1.1 & $0.45(0.40,0.51)$ \\
\hline \multicolumn{9}{|l|}{ Multiple deployments ${ }^{\mathrm{f}}$} \\
\hline One & 169,433 & 62.7 & 6.5 & 1 & 6.5 & 1 & 3.7 & 1 \\
\hline More than one & 100,813 & 37.3 & 7.6 & $1.08(1.04,1.13)^{*}$ & 7.6 & $0.69(0.64,0.76)^{*}$ & 3.1 & $0.77(0.72,0.81)$ \\
\hline
\end{tabular}

a AUD refers to veterans with alcohol use disorders, excluding drug use disorders; DUD refers to veteran with drug use disorders, excluding alcohol use disorders. AUD

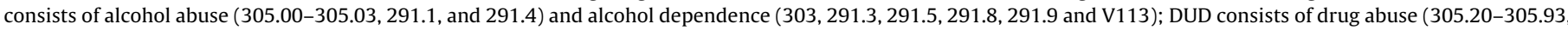

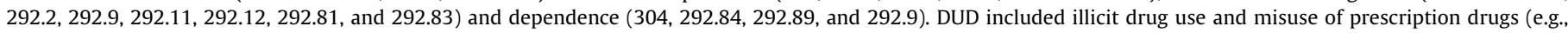
305.406, diazepam (valium) abuse unspecified). AUD and DUD refers to veterans with both AUD and DUD.

b Unadjusted prevalence rate in each sub-category (row percentage).

c Odds ratio (OR) with 95\% confidence intervals (CI) adjusted for sex, age, race/ethnicity, marital status, rank, branch of service and multiple deployments. Please note that

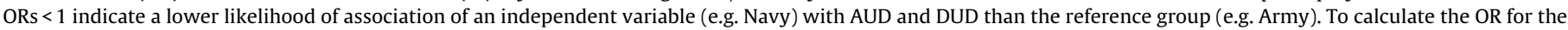

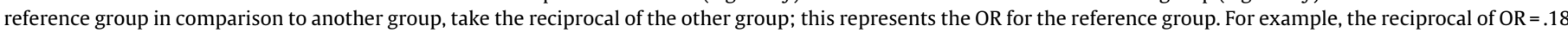

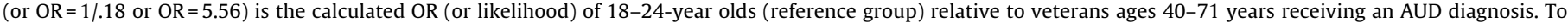
calculate the confidence intervals (CIs), use the reciprocals as well.

d There are missing values.

e Other includes Asian, Pacific Islander, mixed races, and other race/ethnicities.

f Includes deployment to Iraq, Afghanistan or surrounding areas.

$p<0.001$.

served in the Army, and over one-third (37\%) had multiple deployments. Of OEF/OIF veterans who had at least one clinical visit to a VA facility nationwide during the study period, $40 \%$ received one or more ICD-9 CM mental health diagnoses, with PTSD being the most common diagnosis (26\%), followed by depression diagnoses (22\%).

An AUD diagnosis was received by $9.9 \%$ of the overall sample and a DUD diagnosis was received by $4.5 \%$. Any SUD diagnosis, AUD or DUD, was received by $11 \%$, while $3.0 \%$ received both AUD and DUD diagnoses. Diagnoses of substance abuse - alcohol abuse (7.3\%) and drug abuse (3.9\%), were more common than diagnoses of substance dependence - alcohol dependence (5.2\%) and drug dependence $(2.7 \%)$. Male veterans had a higher prevalence overall of SUD (AUD - 10.5\% and DUD - 4.8\%) compared to women veterans (AUD - $4.8 \%$ and DUD - 2.4\%).

\subsection{Correlates of alcohol and drug use disorders in OEF/OIF veterans}

Among OEF/OIF veterans, independent correlates of AUD and DUD, stratified by component type, are shown in Table 1 for AD and Table 2 for NG/R veterans. The youngest group of AD veterans, ages 18-24 years, was significantly more likely than older veterans to have received AUD or DUD diagnoses. The age-associated risk declined in a step-wise fashion with advancing age; the youngest group having over twice the risk of AUD and over 5 times the risk of DUD than $A D$ veterans over age 40 (Table 1, footnote). In contrast, among NG/R veterans, age was not a statistically significant correlate of AUD diagnoses. Of note, the youngest group of NG/R veterans was significantly more likely to receive DUD diagnoses compared to those $>30$ years old, but the magnitude of the decline in risk for DUD with advancing age was smaller than for AD veterans.

Fewer differences between $A D$ and NG/R veterans were observed for other correlates of AUD and DUD diagnoses (Tables 1 and 2). For instance, in both AD and NG/R veterans, men were nearly 1.5 to over two times more likely to receive AUD and DUD diagnoses than female veterans. Among veterans of both components, with one exception, there was a trend for White veterans to be at higher risk for AUD and DUD diagnoses than ethnic minority groups. In addition, compared to married veterans, those who had never been married had a $25 \%$ to $>60 \%$ greater likelihood of 
Table 2

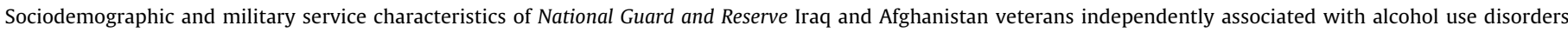
(AUD), drug use disorders (DUD) and both.

\begin{tabular}{|c|c|c|c|c|c|c|c|c|}
\hline \multirow[t]{3}{*}{ Characteristics } & \multirow{2}{*}{\multicolumn{2}{|c|}{$\frac{\text { Total }}{(n=186,256)}$}} & \multirow{2}{*}{\multicolumn{2}{|c|}{$\frac{\text { AUD only }^{\mathrm{a}}}{(n=12,700)}$}} & \multirow{2}{*}{\multicolumn{2}{|c|}{$\frac{\text { DUD only }^{\mathrm{a}}}{(n=2189)}$}} & \multirow{2}{*}{\multicolumn{2}{|c|}{$\frac{\text { AUD and DUD }}{(n=4218)}$}} \\
\hline & & & & & & & & \\
\hline & $n$ & $\% \mathrm{~b}$ & $\%$ & $\mathrm{OR}^{\mathrm{c}}(95 \% \mathrm{CI})$ & $\%$ & $\mathrm{OR}^{\mathrm{c}}(95 \% \mathrm{CI})$ & $\%$ & $\mathrm{OR}^{\mathrm{c}}(95 \% \mathrm{CI})$ \\
\hline \multicolumn{9}{|l|}{$\operatorname{Sex}^{\mathrm{d}}$} \\
\hline Female & 19,647 & 10.5 & 3.6 & 1 & 0.9 & 1 & 1.1 & 1 \\
\hline Male & 166,606 & 89.5 & 7.2 & $2.20(2.03,2.40)^{*}$ & 1.2 & $1.42(1.20,1.66)^{*}$ & 2.4 & $2.67(2.31,3.09)$ \\
\hline \multicolumn{9}{|l|}{ Race $^{\mathrm{d}}$} \\
\hline White & 121,146 & 65.0 & 7.0 & 1 & 1.3 & 1 & 2.3 & 1 \\
\hline Black & 21,750 & 11.7 & 6.7 & $0.99(0.93,1.05)$ & 1.3 & $1.04(0.91,1.19)$ & 2.9 & $1.33(1.21,1.46)^{*}$ \\
\hline Hispanic & 17,313 & 9.3 & 7.1 & $1.00(0.94,1.07)$ & 0.7 & $0.53(0.44,0.64)^{*}$ & 1.7 & $0.75(0.66,0.84)^{*}$ \\
\hline Other ${ }^{\mathrm{e}}$ & 8461 & 4.5 & 5.8 & $0.83(0.74,0.93)^{*}$ & 0.7 & $0.72(0.55,0.95)$ & 1.5 & $0.84(0.69,1.01)$ \\
\hline \multicolumn{9}{|l|}{ Age group (years) $)^{c, d}$} \\
\hline $18-24$ & 44,012 & 23.6 & 7.8 & & 1.6 & 1 & 3.1 & 1 \\
\hline $25-29$ & 43,461 & 23.3 & 7.2 & $0.94(0.89,0.99)$ & 1.5 & $0.91(0.81,1.03)$ & 2.8 & $0.93(0.86,1.02)$ \\
\hline $30-39$ & 47,292 & 25.4 & 6.7 & $0.98(0.92,1.04)$ & 1.0 & $0.65(0.57,0.75)^{*}$ & 1.9 & $0.74(0.67,0.82)^{*}$ \\
\hline $40-71$ & 50,754 & 27.2 & 5.8 & $0.94(0.88,1.00)$ & 0.7 & $0.48(0.41,0.57)^{*}$ & 1.4 & $0.58(0.52,0.65)^{*}$ \\
\hline \multicolumn{9}{|l|}{ Marital status ${ }^{\mathrm{d}}$} \\
\hline Married & 84,043 & 45.1 & 6.2 & 1 & 1.0 & 1 & 1.5 & 1 \\
\hline Never married & 64,560 & 34.7 & 7.9 & $1.25(1.19,1.32)^{*}$ & 1.5 & $1.12(1.00,1.25)$ & 3.1 & $1.63(1.49,1.77)^{*}$ \\
\hline Divorced/separated/widowed & 20,594 & 11.1 & 10.2 & $1.84(1.74,1.95)^{*}$ & 1.6 & $1.61(1.41,1.85)^{*}$ & 4.3 & $3.07(2.80,3.37)^{*}$ \\
\hline \multicolumn{9}{|l|}{ Rank } \\
\hline Enlisted & 170,749 & 91.7 & 7.2 & 1 & 1.3 & 1 & 2.4 & 1 \\
\hline Officer & 15,507 & 8.3 & 2.3 & $0.37(0.33,0.42)^{*}$ & 0.3 & $0.28(0.20,0.39)^{*}$ & 0.3 & $0.17(0.13,0.24)^{*}$ \\
\hline \multicolumn{9}{|l|}{ Branch $^{\mathrm{d}}$} \\
\hline Army & 149,970 & 80.5 & 7.1 & 1 & 1.3 & 1 & 2.4 & 1 \\
\hline Marines & 13,162 & 7.1 & 8.8 & $1.14(1.07,1.23)^{*}$ & 0.9 & $0.56(0.46,0.69)^{*}$ & 2.5 & $0.83(0.73,0.94)$ \\
\hline Navy & 8514 & 4.6 & 4.6 & $0.69(0.62,0.78)^{*}$ & 0.6 & $0.59(0.43,0.81)^{*}$ & 1.0 & $0.46(0.36,0.59)^{*}$ \\
\hline Air Force & 14,573 & 7.8 & 3.6 & $0.60(0.54,0.66)^{*}$ & 0.5 & $0.63(0.48,0.82)^{*}$ & 1.0 & $0.53(0.43,0.64)^{*}$ \\
\hline \multicolumn{9}{|l|}{ Multiple deployments ${ }^{\mathrm{f}}$} \\
\hline One & 117,633 & 63.2 & 6.9 & 1 & 1.3 & 1 & 2.3 & 1 \\
\hline More than one & 68,623 & 36.8 & 6.7 & $1.04(1.00,1.09)$ & 1.0 & $0.91(0.82,1.00)$ & 2.2 & $1.06(0.99,1.14)$ \\
\hline
\end{tabular}

a AUD refers to veterans with alcohol use disorders, excluding drug use disorders; DUD refers to veteran with drug use disorders, excluding alcohol use disorders. AUD

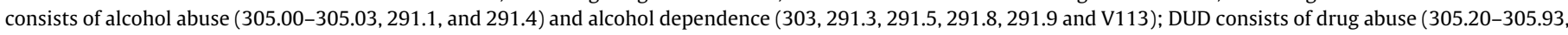

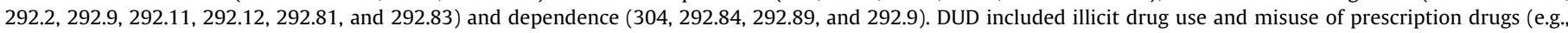
305.406, diazepam (valium) abuse unspecified). AUD and DUD refers to veterans with both AUD and DUD.

b Unadjusted prevalence rate in each sub-category (row percentage).

c Odds ratio (OR) with 95\% confidence intervals (CI) adjusted for sex, age, race/ethnicity, marital status, rank, branch of service and multiple deployments. Please note that

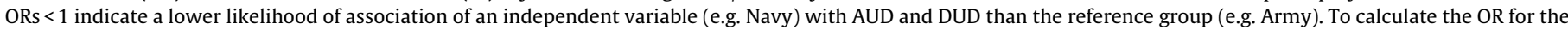

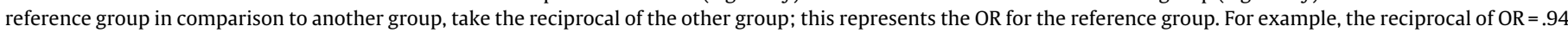

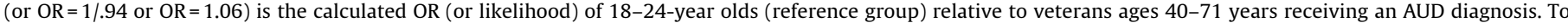
calculate the confidence intervals (CIs), use the reciprocals as well.

d There are missing values.

e Other includes Asian, Pacific Islander, mixed races, and other race/ethnicities.

${ }^{f}$ Includes deployment to Iraq, Afghanistan or surrounding areas.

* $p<0.001$.

receiving AUD or both diagnoses. Veterans of both components who were divorced, separated or widowed had over one and a half to over three times the risk for AUD and DUD diagnoses compared to married veterans.

In general, veterans of both $\mathrm{AD}$ and $\mathrm{NG} / \mathrm{R}$ components who had proxies for greater combat exposure, namely having been junior enlisted (versus officers) and having been in the Army (versus other branches) (Kulka et al., 1990), were at greater risk for AUD and DUD diagnoses. Among AD veterans with multiple deployments, there was a small increased risk for AUD diagnoses, but a decreased risk for DUD and both AUD and DUD diagnoses. Having served multiple deployments was not associated with increased risk for AUD, DUD, or both in NG/R veterans.

\subsection{Comorbidity in OEF/OIF veterans with alcohol and drug use disorders}

Overall, of OEF/OIF veterans with AUD, DUD or both diagnoses, 82-93\% had at least one other comorbid mental health diagnosis
(PTSD, depression, anxiety, and/or adjustment disorder). Table 3 shows the adjusted odds of the association of four target mental health disorders with AUD and DUD. Among OEF/OIF veterans who used VA healthcare, 63\% with AUD or DUD diagnoses and 76\% with both AUD and DUD diagnoses also received comorbid PTSD diagnoses (Fig. 1). Having received a PTSD diagnosis increased the odds of an AUD diagnosis by roughly 4-fold and a DUD diagnosis by roughly 3 -fold. Similarly, depression was also associated with significantly increased AUD, DUD and both diagnoses. The prevalence and odds of receiving comorbid anxiety and adjustment disorders diagnoses were also significantly elevated in the context of receiving AUD, DUD or both diagnoses, but the magnitude of the effect sizes were smaller.

Table 4 shows that the independent odds of having 3 or more comorbid mental health diagnoses in addition to AUD, DUD or both ranged from 1.95 to 2.81 . Of note, only $1 \%$ of veterans received a diagnosis of isolated AUD (without DUD or any other mental health disorder), while only $0.2 \%$ of veterans received an isolated DUD diagnosis (without AUD or other mental health disorders). 
Table 3

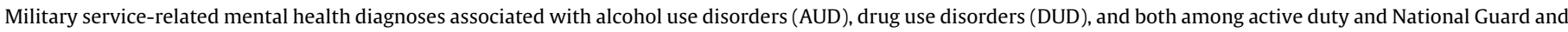
Reserve veterans of Iraq and Afghanistan.

\begin{tabular}{|c|c|c|c|c|c|c|c|c|}
\hline \multirow[t]{3}{*}{ Mental health diagnoses ${ }^{\mathrm{a}}$} & \multirow{2}{*}{\multicolumn{2}{|c|}{$\frac{\text { Total }}{(n=456,502)}$}} & \multirow{2}{*}{\multicolumn{2}{|c|}{$\frac{\text { AUD }^{\mathrm{b}}}{(n=31,479)}$}} & \multirow{2}{*}{\multicolumn{2}{|c|}{$\frac{\text { DUD }^{\mathrm{b}}}{(n=6973)}$}} & \multirow{2}{*}{\multicolumn{2}{|c|}{$\frac{\text { AUD and DUD }}{(n=13,533)}$}} \\
\hline & & & & & & & & \\
\hline & $n$ & $\% \mathrm{c}$ & $\% \mathrm{c}$ & $\mathrm{OR}^{\mathrm{d}}(95 \% \mathrm{CI})$ & $\% \mathrm{c}$ & $\mathrm{OR}^{\mathrm{d}}(95 \% \mathrm{CI})$ & $\% c$ & $\mathrm{OR}^{\mathrm{d}}(95 \% \mathrm{CI})$ \\
\hline \multicolumn{9}{|l|}{ PTSD } \\
\hline No & 337,504 & 73.9 & 37.0 & 1 & 36.6 & 1 & 23.9 & 1 \\
\hline Yes & 118,998 & 26.1 & 63.0 & $4.01(3.79,4.25)^{*}$ & 63.4 & $3.08(2.84,3.34)^{*}$ & 76.1 & $4.33(3.92,4.79)^{*}$ \\
\hline \multicolumn{9}{|l|}{ Depression } \\
\hline No & 356,685 & 78.1 & 46.4 & 1 & 41.9 & 1 & 28.1 & 1 \\
\hline Yes & 99,817 & 21.9 & 53.6 & $3.61(3.44,3.78)^{*}$ & 58.1 & $3.18(2.93,3.45)^{*}$ & 71.9 & $4.68(4.33,5.06)^{*}$ \\
\hline \multicolumn{9}{|l|}{ Anxiety } \\
\hline No & 394,712 & 86.5 & 70.2 & 1 & 61.8 & 1 & 56.1 & 1 \\
\hline Yes & 61,790 & 13.5 & 29.8 & $2.10(1.99,2.21)$ & 38.2 & $2.54(2.32,2.78)^{*}$ & 43.9 & $2.55(2.39,2.73)^{*}$ \\
\hline \multicolumn{9}{|l|}{ Adjustment disorder } \\
\hline No & 396,660 & 86.9 & 73.5 & 1 & 71.7 & 1 & 66.4 & 1 \\
\hline Yes & 59,842 & 13.1 & 26.5 & $1.81(1.72,1.91)^{*}$ & 28.3 & $1.82(1.67,1.98)^{*}$ & 33.6 & $1.72(1.60,1.85)^{*}$ \\
\hline
\end{tabular}

a The following ICD-9 CM codes were used to define: PTSD (ICD-9 CM code 309.81), depressive disorders (296.2-296.25, 296.30-296.35, and 300.4 and 311.0), anxiety disorders (300.0-300.09, 300.20-300.29, and 300.3) and adjustment disorders (309.0-309.9).

b AUD refers to veterans with alcohol use disorders, excluding drug use disorders; DUD refers to veteran with drug use disorders, excluding alcohol use disorders. AUD

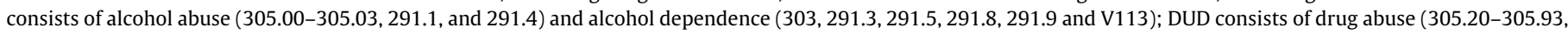

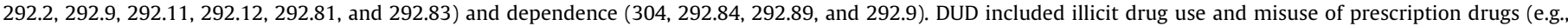
305.406, diazepam (valium) abuse unspecified). AUD and DUD refers to veterans with both AUD and DUD.

c Unadjusted prevalence rate (column percentage).

d Odds ratio (OR) with 95\% confidence intervals (CI) adjusted for sociodemographic and military service characteristics, number of primary care visits, number of mental health visits, and clustering by VA facility.

${ }^{*} p<0.001$.

Table 4

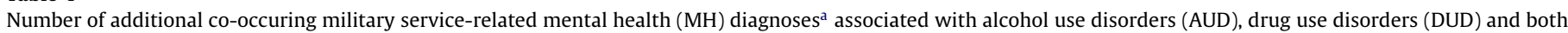
among active duty and National Guard and Reserve veterans of Iraq and Afghanistan.

\begin{tabular}{|c|c|c|c|c|c|c|c|c|}
\hline \multirow[t]{3}{*}{ Number of additional co-occurring $\mathrm{MH}$ disorders ${ }^{\mathrm{a}}$} & \multirow{2}{*}{\multicolumn{2}{|c|}{$\frac{\text { Total }}{(n=456,502)}$}} & \multirow{2}{*}{\multicolumn{2}{|c|}{$\frac{\text { AUD }^{\mathrm{b}}}{(n=31,479)}$}} & \multirow{2}{*}{\multicolumn{2}{|c|}{$\frac{\text { DUD }^{\mathrm{b}}}{(n=6973)}$}} & \multirow{2}{*}{\multicolumn{2}{|c|}{$\frac{\text { AUD } \text { and DUD }}{\mathrm{b}}$}} \\
\hline & & & & & & & & \\
\hline & $n$ & $\% \mathrm{c}$ & $\% \mathrm{c}$ & $\mathrm{OR}^{\mathrm{d}}(95 \% \mathrm{CI})$ & $\%^{c}$ & $\mathrm{OR}^{\mathrm{d}}(95 \% \mathrm{CI})$ & $\% \mathrm{c}$ & $\mathrm{OR}^{\mathrm{d}}(95 \% \mathrm{CI})$ \\
\hline 1 additional MH diagnosis & 72,480 & 15.9 & 23.3 & 1 & 22.9 & 1 & 16.4 & 1 \\
\hline 2 additional $\mathrm{MH}$ diagnoses & 64,246 & 14.1 & 33.1 & $1.68(1.61,1.76)^{*}$ & 31.1 & $1.39(1.28,1.51)^{*}$ & 32.7 & $1.87(1.72,2.03)^{*}$ \\
\hline$\geq 3$ additional $\mathrm{MH}$ diagnoses & 43,625 & 9.6 & 26.0 & $1.98(1.87,2.09)^{*}$ & 31.6 & $1.95(1.77,2.15)^{*}$ & 43.9 & $2.81(2.56,3.09)^{*}$ \\
\hline
\end{tabular}

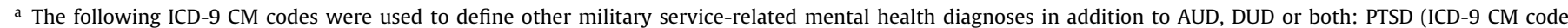

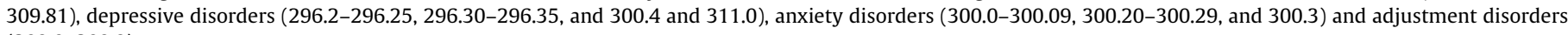
(309.0-309.9).

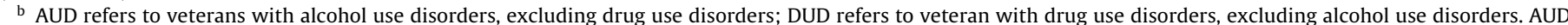

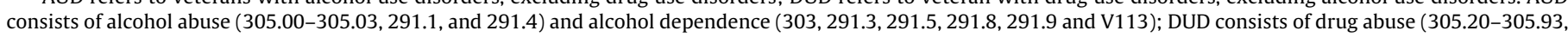

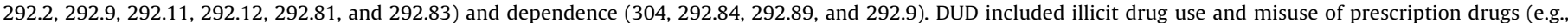
305.406, diazepam (valium) abuse unspecified). AUD and DUD refers to veterans with both AUD and DUD.

c Unadjusted prevalence rate (column percentage).

d Odds ratio (OR) with 95\% confidence intervals (CI) adjusted for sociodemographic and military service characteristics, number of primary care visits, number of mental health visits, and clustering by VA facility.

* $p<0.001$.

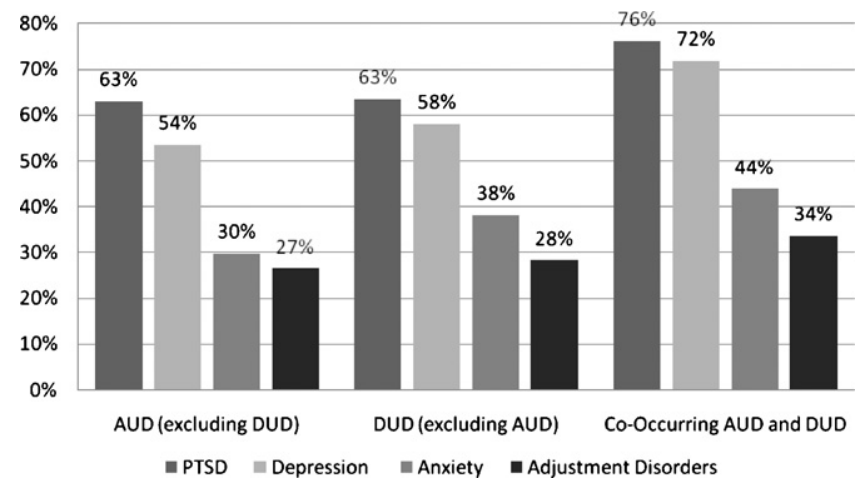

Fig. 1. Unadjusted prevalence of comorbid military service-related mental health diagnoses (PTSD, depression, anxiety and adjustment disorders) associated with alcohol use disorders (AUD), drug use disorders (DUD), and both among active duty and National Guard and Reserve veterans of Iraq and Afghanistan.

\section{Discussion}

The prevalence of AUD diagnoses in OEF/OIF veterans in VA healthcare (10\%; $10.5 \%$ of men and $4.5 \%$ of women) is similar to the prevalence of AUD diagnoses reported in prior epidemiologic surveys of Vietnam Veterans, which found that $11.2-14 \%$ of males (Centers for Disease Control, 1988; Kulka et al., 1990) and 2.4\% of females (Kulka et al., 1990) met DSM-III criteria for a current AUD diagnosis. This similarity is notable because our results were based on the entire population of OEF/OIF veterans nationwide who sought VA treatment and received ICD-9 diagnoses associated with clinical visits, whereas the studies cited above were derived from nationally representative samples of Vietnam veterans undergoing standardized diagnostic interviews. Of note, the lifetime prevalence of AUD diagnoses in the National Vietnam Veterans Readjustment Study (NVVRS) cohort was 39.2\% in men and 9.1\% in women (Kulka et al., 1990), which, given the similarities in cur- 
rent prevalence, may foreshadow a parallel lifetime prevalence of AUD in OEF/OIF veterans over time. Prospective longitudinal studies from nationally representative samples of OEF/OIF veterans are underway (Department of Veterans Affairs, 2009b), and these may allow estimation of future public health burden.

AUD diagnostic rates of OEF/OIF veterans in this study were higher than civilian AUD prevalence rates, which range from 3.1\% to 8.5\% (Hasin et al., 2007; Kessler et al., 2005; Regier et al., 1990). Combat exposure has been associated with higher rates of alcohol and substance misuse (Calhoun et al., 2008; Jacobson et al., 2008), and drinking is an established part of military culture (Ames and Cunradi, 2004/2005). Rates of AUD diagnoses in OEF/OIF veterans using VA healthcare were lower than rates of positive screens for high-risk alcohol use in OEF/OIF military service personnel and veterans (12-22\%) (Hawkins et al., 2010; Milliken et al., 2007; Riddle et al., 2007; Santiago et al., 2010). A higher rate of positive screens for at-risk drinking compared to AUD diagnoses would be expected because screens are designed to be more sensitive. The military is aware of the short and long-term consequences of problem drinking and now conducts universal screening for high-risk alcohol use (Department of Defense, 2005b, 2006a, 2008a,b; Santiago et al., 2010). Nevertheless, studies have shown that universal screening of military and veteran populations for mental health problems does not necessarily lead to improved clinical outcomes (Milliken et al., 2007; Rona et al., 2005; Seal et al., 2008). Thus, in addition to screening, the military has sponsored media campaigns against high-risk drinking, but additional prevention strategies may be needed (Department of Defense, 2005a, 2006b).

Among OEF/OIF veterans who were first-time users of VA healthcare, $4.5 \%$ received a DUD diagnosis (4.8\% of male veterans and $2.4 \%$ of women). In contrast, in the NVVRS cohort, current DUD diagnosis rates were lower: $1.8 \%$ among male Vietnam veterans and 0\% among female veterans (Kulka et al., 1990). Epidemiological surveys of civilians also found lower DUD prevalence rates of 1.4-2.0\% (Compton et al., 2007; Kessler et al., 2005; Regier et al., 1990). Neither VA nor the military conducts universal screening for non-alcohol substance misuse. Disclosure of drug misuse often involves personal stigma and the disclosure of illegal activities, both disincentives for clinicians to ask and for patients to respond truthfully. In addition, funding for VA substance abuse treatment programs has declined relative to other healthcare services (Chen et al., 2003; Chen et al., 2001), and many substance abuse treatment programs accept patients only after abstinence is achieved, two factors that limit the utility of universal screening.

This lack of screening for DUD raises the concern that the true rates of DUD in OEF/OIF veterans using VA may be higher than the diagnostic prevalence rates reported in this study. Indeed, a recent independent Survey of Health-Related Behaviors administered to 28,500 AD military personnel world-wide in 2008 found that $12 \%$ reported illicit drug use (Bray et al., 2009). This represents an increase from 5\% in 2005 (Bray et al., 2006), and was primarily attributed to a rise in prescription drug misuse (Bray et al., 2009). Although the study was not exclusive to OEF/OIF military personnel, its findings merit consideration because many more OEF/OIF soldiers and veterans are surviving injuries than in prior conflicts (Gawande, 2004) and using narcotic pain medication for injuries (Wu et al., 2010).

In fact, we found that extremely few veterans in our study received isolated DUD diagnoses $(0.2 \%)$ which may reflect Berkson's bias (Berkson, 1946). In other words, clinicians may not be asking about or detecting DUD unless veterans present for other mental health problems. Given the lack of universal screening for substance misuse, and indications that DUD diagnostic rates may be higher in OEF/OIF veterans than in other-era veterans or in civilians, clinicians could improve care by using psychoeducation to destigmatize problem drug use and by assessing OEF/OIF veterans for drug use, whether or not another mental health disorder is present.

We identified several subgroups with increased risk for AUD and DUD diagnoses. The highest relative risk for AUD and DUD was found in the very youngest group of AD veterans (ages 18-24 years), a finding corroborated by other studies (Calhoun et al., 2008; Jacobson et al., 2008). In contrast, we found nearly the same risk for AUD among older and younger groups of NG/R veterans, which is consistent with other studies which have highlighted problem drinking in NG/R veterans (Iowa Persian Gulf Study Group, 1997; Jacobson et al., 2008; Milliken et al., 2007). National Guard and Reserve veterans of all ages may be at high risk for SUD after returning home because when called to arms they are more likely established in civilian occupations, have family and community ties, and may have had less preparation for combat, making their transition to warzone and home again more challenging (Friedman 2005; Jacobson et al., 2008). Thus, clinicians should probe for alcohol and drug misuse, especially in the youngest group of OEF/OIF veterans and in NG/R veterans of all ages.

In both $\mathrm{AD}$ and $\mathrm{NG} / \mathrm{R}$ veterans, we found that proxies for combat exposure (Kulka et al., 1990), namely being enlisted (versus officer) and in the Army or Marines (versus other branches) were associated with increased rates of AUD and DUD diagnoses as shown in prior studies (Hoge et al., 2006; Jakupcak et al., 2010; Reger et al., 2009; Wilk et al., 2010). Nevertheless, as in other studies (Reger et al., 2009), we did not find a consistent positive association with number of deployments and AUD and DUD diagnoses. One explanation is that veterans who exhibit mental health problems, including SUD, may be less likely to redeploy (Hoge et al., 2006).

Other sociodemographic factors, such as being male or unmarried (never married or separated, divorced or widowed) were also significantly associated with AUD and DUD diagnoses. Prior studies have demonstrated that following deployment, men are more likely to develop SUDs, whereas women tend to develop depression (Jacobson et al., 2008; Lapierre et al., 2007; Tanielian and Jaycox, 2008; Wells et al., 2010). Indeed, a recent study of OEF/OIF veterans within the VA healthcare system confirmed that men are more likely to have SUDs, whereas women are more likely to have depression (Maguen et al., 2010). In addition, being unmarried or divorced may signify poorer social support or lack of close personal relationships, which have been shown to be risk factors for military service-related mental health problems (Boscarino, 1995; Reger et al., 2009; Wilk et al., 2010). This finding underscores the need for substance abuse prevention for returning OEF/OIF veterans who are at high risk for developing SUDs in the post-deployment period, such as those with limited social support.

The vast majority (80-95\%) of veterans had at least one other comorbid mental health diagnosis in addition to AUD and DUD diagnoses. Indeed, veterans had three to four times the odds of receiving comorbid PTSD and depression diagnoses in association with AUD and DUD diagnoses. Our findings are consistent with prior studies of treatment-seeking male veterans who demonstrated high comorbidity rates of combat-related PTSD and SUD (Hyer et al., 1991; McFall et al., 1992; Roszell et al., 1991; Sierles et al., 1983). Our findings are also consistent with the NVVRS cohort, in which $73 \%$ of male Vietnam veterans met diagnostic criteria for comorbid PTSD and a lifetime diagnosis of AUD (Kulka et al., 1990). Prospective longitudinal studies have demonstrated that PTSD and depression symptoms precede or exacerbate drug and alcohol misuse, supporting the hypothesis that self-medication of psychiatric symptoms drives substance abuse in the context of PTSD and/or depression (Bremner et al., 1996; Breslau et al., 2003; Chilcoat and Breslau, 1998; Jakupcak et al., 2010). Similarly, human laboratory studies have shown that emotional stress and negative affect states increase drug craving (Sinha, 2009). 
Individuals with dual diagnoses of SUD and co-occurring mental disorders often have more severe symptoms and poorer treatment outcomes than individuals with a single non-substance use mental health disorder (Kessler et al., 1996; Ouimette et al., 1998a, 1997; Watkins et al., 2001). Traditionally, mental health treatment programs, including those in VA, have used a sequential approach, treating SUDs first with the goal of achieving stabilization or abstinence prior to initiating treatment for other mental health conditions (Ruzek, 2002). Although VA has been a leader in exploring the integration of PTSD and SUD treatment with the establishment of substance use and PTSD treatment programs (SUPT), the number of funded programs has declined from 15 to 5 such programs currently (Northeastern Program Evaluation Center, 2007).

The dearth of dedicated integrated dual diagnosis treatment programs may be due to the small number of randomized controlled trials to date demonstrating their clinical efficacy (Hien et al., 2004, 2009; Norman et al., 2010). In contrast, there have been several uncontrolled smaller studies of the treatment of co-occurring PTSD and SUD that strongly suggest that adding trauma-focused interventions to SUD treatment, such as "Seeking Safety" (Najavits, 2002), which is widely used in VA, results in significant decreases in both PTSD and SUD symptoms (Brady et al., 2001; Morrissey et al., 2005; Najavits et al., 2005, 1998). Indeed, the Iraq War Clinician Guide states that, “'Seeking Safety' should be considered a treatment option for Iraq War veterans who have substance use disorders along with problematic traumatic stress responses" (National Center for PTSD and Walter Reed Army Medical Center, 2004). In addition, the VA Uniform Mental Health Services Handbook (Department of Veterans Affairs, 2008) and VA/DoD Clinical Practice Guidelines (Department of Veterans Affairs and Department of Defense, 2009) encourage a minimum of "coordinated care" for individuals with co-occuring disorders. Clearly, more randomized controlled studies of integrated treatments for dual diagnoses are needed to further guide the implementation of these programs in VA and other healthcare systems, particularly in light of the high numbers of OEF/OIF veterans with co-occurring SUD diagnoses and other mental health diagnoses.

Some limitations apply to our findings. First, our results are based on a treatment-seeking population of OEF and OIF veterans enrolled in VA health care, and thus our findings may not generalize to all separated OEF and OIF veterans. Nevertheless, our results represent nearly the entire treatment-seeking population of $\mathrm{OEF} / \mathrm{OIF}$ veterans in VA healthcare and the VA is the single largest provider of healthcare for returning combat veterans. Second, we relied on ICD-9 CM administrative codes for mental health diagnoses associated with clinical visits, which have been shown to be a valid proxy for estimating disease (Borzecki et al., 2004; Movig et al., 2003), but may have introduced potential system, provider and patient ascertainment biases, which could either over- or under-estimate true SUD diagnostic rates. For instance, veterans with greater clinical need, as a result of problem drinking or drug abuse, may have been more likely to seek care and hence receive diagnoses (Elhai and Ford, 2007; Elhai et al., 2008). On the other hand, veterans with SUD may have experienced greater stigma or denial or greater logistical challenges to accessing care (Hoge et al., 2004; Kim et al., 2010; Tanielian and Jaycox, 2008), leading to under-estimates. In addition, clinicians sensitive to stigma or lacking time or training may have failed to ask their patients about substance misuse or omitted these diagnoses from the electronic medical record, which would also lower frequencies of documented diagnoses.

Despite these limitations, this is the first study to report the prevalence and predictors of alcohol and drug use disorder diagnoses in nearly half a million Iraq and Afghanistan veterans who are first-time users of VA healthcare nationwide. Overall, $11 \%$ of these OEF/OIF veteran patients received diagnoses of AUD, DUD or both; $10 \%$ received AUD diagnoses and 5\% received DUD diagnoses. These rates are similar to or higher than SUD rates in prior-era veterans. We identified that AUD and DUD diagnoses were more likely in particular subgroups of Iraq and Afghanistan veterans: active duty veterans, veterans under age 25 , men, unmarried veterans, and veterans with likely greater combat exposure, i.e., those who were enlisted (versus officers) and had served in the Army and Marines as opposed to other branches. These data may be useful in informing VA and other national healthcare systems in developing clinical algorithms for improved detection and intervention for SUDs in returning combat veterans, particularly for DUD given the lack of screening and heightened stigma. Our findings suggest a need for further research on integrated mental health treatments, as the vast majority of OEF/OIF veterans with SUD suffer from dual diagnoses related to military service.

\section{Conflicts of interest}

None of the authors has any actual or potential conflict of interest, including any financial, personal, or other relationships that inappropriately influenced the analyses or content of this manuscript.

\section{Role of funding source}

This study was funded by a VA Health Services Research and Development (HSR\&D) Career Development Award and by a Department of Defense Award (W81XWH-05-2-0094). Dr. Waldrop was supported by a K23 DA018718. Dr. Cohen was supported by a K23 HL 094765-01. Dr. Maguen was supported by a VA HSR\&D Career Development Award. The funders had no role in the design and conduct of the study; collection, management, analysis, and interpretation of the data; and preparation, review or approval of the manuscript.

\section{Contributors}

Drs. Seal, Maguen, Cohen, and Waldrop and Ms. Ren were involved in the design of the secondary data analyses. Mr. Cohen contributed to the literature review and helped to summarize previous work. Ms. Ren conducted statistical analyses, which were overseen and interpreted by Dr. Seal. Dr. Seal takes responsibility for the integrity of the data and accuracy of the data analysis. All authors had full access to all the data in the study. Dr. Seal and Mr. Cohen drafted the manuscript. All authors approved the final manuscript.

\section{Acknowledgements}

The authors wish to acknowledge the service and courage of the men and women who have served in Iraq, Afghanistan and surrounding areas. We also wish to acknowledge Mr. Daniel Bertenthal of the San Francisco VA Medical Center HSR\&D Research Enhancement Award Program who provided consultation on the use of VA national-level data.

\section{References}

American Psychiatric Association, 2000. Diagnostic and Statistical Manual of Mental Disorders, 4th edition, text revision. American Psychiatric Association, Washington, DC.

Ames, G., Cunradi, C., 2004/2005. Alcohol use and preventing alcohol-related problems among young adults in the military. Alcohol Res. Health 28, 252-257.

Ashton, C., Souchek, J., Petersen, N., Menke, T., Collins, T., Kizer, K., Wright, S., Wray, N., 2003. Hospital use and survival among Veterans Affairs beneficiaries. N. Engl. J. Med. 349, 1637-1646. 
Associated Press, 2008. Pentagon Totals Rise for Stress Disorder. New York Times, New York, NY.

Berkson, J., 1946. Limitations of the application of fourfold table analysis to hospital data. Biometrics Bull. 2, 47-53.

Borzecki, A.M., Wong, A.T., Hickey, E.C., Ash, A.S., Berlowitz, D.R., 2004. Identifying hypertension-related comorbidities from administrative data: what's the optimal approach? Am. J. Med. Qual. 19, 201-206.

Boscarino, J.A., 1995. Post-traumatic stress and associated disorders among Vietnam veterans: the significance of combat exposure and social support. J. Trauma Stress 8, 317-336.

Boyko, E.J., Koepsell, T.D., Gaziano, J.M., Horner, R.D., Feussner, J.R., 2000. US Department of Veterans Affairs medical care system as a resource to epidemiologists. Am. J. Epidemiol. 151, 307-314.

Brady, K.T., Dansky, B.S., Back, S.E., Foa, E.B., Carroll, K.M., 2001. Exposure therapy in the treatment of PTSD among cocaine-dependent individuals: preliminary findings. J. Subst. Abuse Treat. 21, 47-54.

Bray, R.M., Hourani, L.L., Olmstead, K.L.R., Witt, M., Brown, J.M., Pemberton, M.R., Marsden, M.E., Marriott, B., Scheffler, S., Vandermaas-Peeler, R., Weimer, B., Calvin, S., Bradshaw, M., Close, K., Hayden, D., 2006. Department of Defense Survey of Health Related Behaviors Among Military Personnel. Research Triangle Institute, Research Triangle Park, NC.

Bray, R.M., Pemberton, M.R., Hourani, L.L., Witt, M., Olmsted, K.L.R., Brown, J.M., Weimer, B., Lane, M.E., Marsden, M.E., Scheffler, S., Vandermaas-Peeler, R., Aspinwall, K.R., Anderson, E., Spagnola, K., Close, K., Gratton, J.L., Calvin, S., Bradshaw, M., 2009. [2008] Department of Defense Survey of Health Related Behaviors Among Active Duty Military Personnel. Research Triangle Institute, Research Triangle Park, NC.

Bremner, J.D., Southwick, S.M., Darnell, A., Charney, D.S., 1996. Chronic PTSD in Vietnam combat veterans: course of illness and substance abuse. Am. J. Psychiatry $153,369-375$.

Breslau, N., Davis, G.C., Schultz, L.R., 2003. Posttraumatic stress disorder and the incidence of nicotine, alcohol, and other drug disorders in persons who have experienced trauma. Arch. Gen. Psychiatry 60, 289294.

Calhoun, P.S., Elter, J.R., Jones, E.R., Kudler, H., Straits-Troster, K., 2008. Hazardous alcohol use and receipt of risk-reduction counseling among U.S. veterans of the wars in Iraq and Afghanistan. J. Clin. Psychiatry 69, 1686-1693.

Centers for Disease Control, 1988. Health status of Vietnam veterans. I. Psychosocial characteristics. The Centers for Disease Control Vietnam Experience Study. JAMA 259, 2701-2707.

Chen, S., Smith, M.W., Wagner, T.H., Barnett, P.G., 2003. Spending for specialized mental health treatment in The VA: 1995-2001. Health Aff. (Millwood) 22, 256-263.

Chen, S., Wagner, T.H., Barnett, P.G., 2001. The effect of reforms on spending for veterans' substance abuse treatment, 1993-1999. Health Aff. (Millwood) 20, $169-175$.

Chilcoat, H.D., Breslau, N., 1998. Posttraumatic stress disorder and drug disorders: testing causal pathways. Arch. Gen. Psychiatry 55, 913-917.

Compton, W.M., Thomas, Y.F., Stinson, F.S., Grant, B.F., 2007. Prevalence, correlates, disability, and comorbidity of DSM-IV drug abuse and dependence in the United States: results from the national epidemiologic survey on alcohol and related conditions. Arch. Gen. Psychiatry 64, 566-576.

Department of Defense, 2005a. Healthy Choices for Life Campaign, http://tricare.mil/ mybenefit/home/overview/SpecialPrograms/HealthyChoicesForLife (accessed 5.25.2010).

Department of Defense, 2005b. Post-Deployment Health Reassessment (PDHRA) Program, http://www.pdhealth.mil/dcs/pdhra.asp (accessed 5.25.2010).

Department of Defense, 2006a. Enhanced Post-Deployment Health Assessment (PDHA) Process, http://www.pdhealth.mil/dcs/DD_form_2796.asp (accessed 5.25.2010).

Department of Defense, 2006b. That Guy, http://www.thatguy.com (accessed 5.25.2010).

Department of Defense, 2008a. Post-Deployment Health Assessment (PDHA) Form (DD Form 2796), http://www.dtic.mil/whs/directives/infomgt/forms/ eforms/dd2796.pdf (accessed 5.25.2010).

Department of Defense, 2008b. Post-Deployment Health Re-Assessment (PDHRA) Form (DD Form 2900), http://www.dtic.mil/whs/directives/infomgt/forms/ eforms/dd2900.pdf (accessed 5.25.2010).

Department of Veterans Affairs, 2008. Uniform Mental Health Services in VA Medical Centers and Clinics. Department of Veterans Affairs, Washington, DC.

Department of Veterans Affairs, Department of Defense, 2009. VA/DoD Clinical Practice Guideline for Management of Substance Use Disorders (SUD).

Department of Veterans Affairs, 2009b. National Health Study for a New Generation of U.S. Veterans, http://www.publichealth.va.gov/research/epidemiology/ newgenerationhealthstudy/index (accessed 5.25.2010).

Department of Veterans Affairs, 2010. Analysis of VA Health Care Utilization Among Operation Enduring Freedom (OEF) and Operation Iraqi Freedom (OIF) Veterans. Office of Public Health and Environmental Hazards, Department of Veterans Affairs, Washington, DC.

Elhai, J.D., Ford, J.D., 2007. Correlates of mental health service use intensity in the National Comorbidity Survey and National Comorbidity Survey Replication. Psychiatr. Serv. 58, 1108-1115.

Elhai, J.D., Grubaugh, A.L., Richardson, J.D., Egede, L.E., Creamer, M., 2008. Outpatient medical and mental healthcare utilization models among military veterans: results from the 2001 National Survey of Veterans. J. Psychiatr. Res. 42, 858867.
Erbes, C., Westermeyer, J., Engdahl, B., Johnsen, E., 2007. Post-traumatic stress disorder and service utilization in a sample of service members from Iraq and Afghanistan. Mil. Med. 172, 359-363.

Friedman, M.J., 2005. Veterans' mental health in the wake of war. N. Engl. J. Med. $352,1287-1290$.

Friedman, M.J., 2010. Prevention of psychiatric problems among military personne and their spouses. N. Engl. J. Med. 362, 168-170.

Gawande, A., 2004. Casualties of war-military care for the wounded from Iraq and Afghanistan. N. Engl. J. Med. 351, 2471-2475.

Grant, B.F., Stinson, F.S., Dawson, D.A., Chou, S.P., Dufour, M.C., Compton, W. Pickering, R.P., Kaplan, K., 2004. Prevalence and co-occurrence of substance use disorders and independent mood and anxiety disorders: results from the National Epidemiologic Survey on Alcohol and Related Conditions. Arch. Gen. Psychiatry 61, 807-816

Hasin, D.S., Stinson, F.S., Ogburn, E., Grant, B.F., 2007. Prevalence, correlates, disability, and comorbidity of DSM-IV alcohol abuse and dependence in the United States: results from the National Epidemiologic Survey on Alcohol and Related Conditions. Arch. Gen. Psychiatry 64, 830-842.

Hawkins, E.J., Lapham, G.T., Kivlahan, D.R., Bradley, K.A., 2010. Recognition and management of alcohol misuse in OEF/OIF and other veterans in the VA: a cross-sectional study. Drug Alcohol Depend. 109, 147-153.

Hien, D.A., Cohen, L.R., Miele, G.M., Litt, L.C., Capstick, C., 2004. Promising treatments for women with comorbid PTSD and substance use disorders. Am. J. Psychiatry $161,1426-1432$.

Hien, D.A., Wells, E.A., Jiang, H., Suarez-Morales, L., Campbell, A.N., Cohen, L.R., Miele, G.M., Killeen, T., Brigham, G.S., Zhang, Y., Hansen, C., Hodgkins, C., HatchMaillette, M., Brown, C., Kulaga, A., Kristman-Valente, A., Chu, M., Sage, R. Robinson, J.A., Liu, D., Nunes, E.V., 2009. Multisite randomized trial of behavioral interventions for women with co-occurring PTSD and substance use disorders. J. Consult. Clin. Psychol. 77, 607-619.

Hoge, C.W., Auchterlonie, J.L., Milliken, C.S., 2006. Mental health problems, use of mental health services, and attrition from military service after returning from deployment to Iraq or Afghanistan. JAMA 295, 1023-1032.

Hoge, C.W., Castro, C.A., Messer, S.C., McGurk, D., Cotting, D.I., Koffman, R.L., 2004. Combat duty in Iraq and Afghanistan, mental health problems, and barriers to care. N. Engl. J. Med. 351, 13-22.

Hyer, L., Leach, P., Boudewyns, P.A., Davis, H., 1991. Hidden PTSD in substance abuse inpatients among Vietnam veterans. J. Subst. Abuse Treat. 8, 213-219.

Iowa Persian Gulf Study Group, 1997. Self-reported illness and health status among Gulf War veterans. A population-based study. JAMA 277, 238-245.

Jacobson, I.G., Ryan, M.A., Hooper, T.I., Smith, T.C., Amoroso, P.J., Boyko, E.J., Gackstetter, G.D., Wells, T.S., Bell, N.S., 2008. Alcohol use and alcohol-related problems before and after military combat deployment. JAMA 300, 663-675.

Jakupcak, M., Tull, M.T., McDermott, M.J., Kaysen, D., Hunt, S., Simpson, T., 2010. PTSD symptom clusters in relationship to alcohol misuse among Iraq and Afghanistan war veterans seeking post-deployment VA health care. Addict. Behav. 35, 840-843.

Kessler, R.C., 2004. The epidemiology of dual diagnosis. Biol. Psychiatry 56, 730 737.

Kessler, R.C., Chiu, W.T., Demler, O., Walters, E.E., 2005. Prevalence, severity, and comorbidity of 12-month DSM-IV disorders in the National Comorbidity Survey Replication. Arch. Gen. Psychiatry 62, 617-627.

Kessler, R.C., Nelson, C.B., McGonagle, K.A., Edlund, M.J., Frank, R.G., Leaf, P.J., 1996. The epidemiology of co-occurring addictive and mental disorders: implications for prevention and service utilization. Am. J. Orthopsychiatry 66, 17-31.

Kim, P.Y., Thomas, J.L., Wilk, J.E., Castro, C.A., Hoge, C.W., 2010. Stigma, barriers to care, and use of mental health services among active duty and National Guard soldiers after combat. Psychiatr. Serv. 61, 582-588.

Kulka, R.A., Schlenger, W.E., Fairbank, J.A., Hough, R.L., Jordan, B.K., Marmar, C.R., Weiss, D.S., 1990. Trauma and the Vietnam War Generation: Report of Findings from the National Vietnam Veterans Readjustment Study. Brunner/Mazel, New York, NY.

Lapierre, C.B., Schwegler, A.F., Labauve, B.J., 2007. Posttraumatic stress and depression symptoms in soldiers returning from combat operations in Iraq and Afghanistan. J. Trauma Stress 20, 933-943.

Maguen, S., Ren, L., Bosch, J., Marmar, C., Seal, K., 2010. Gender differences in mental health diagnoses among Iraq and Afghanistan veterans enrolled in veterans affairs health care. Am. J. Public Health 100, 2450-2456.

McDevitt-Murphy, M.E., Williams, J.L., Bracken, K.L., Fields, J.A., Monahan, C.J., Murphy, J.G., 2010. PTSD symptoms, hazardous drinking, and health functioning among U.S. OEF and OIF veterans presenting to primary care. J. Trauma Stress. 23, 108-111.

McFall, M.E., Mackay, P.W., Donovan, D.M., 1992. Combat-related posttraumatic stress disorder and severity of substance abuse in Vietnam veterans. J. Stud. Alcohol 53, 357-363.

Milliken, C.S., Auchterlonie, J.L., Hoge, C.W., 2007. Longitudinal assessment of mental health problems among active and reserve component soldiers returning from the Iraq war. JAMA 298, 2141-2148.

Morrissey, J.P., Jackson, E.W., Ellis, A.R., Amaro, H., Brown, V.B., Najavits, L.M., 2005 Twelve-month outcomes of trauma-informed interventions for women with co-occurring disorders. Psychiatr. Serv. 56, 1213-1222.

Movig, K.L., Leufkens, H.G., Lenderink, A.W., Egberts, A.C., 2003. Validity of hospital discharge International Classification of Diseases (ICD) codes for identifying patients with hyponatremia. J. Clin. Epid. 56, 530-535. 
Najavits, L., 2002. Seeking Safety: A Treatment Manual for PTSD and Substance Abuse. Guilford, New York.

Najavits, L.M., Schmitz, M., Gotthardt, S., Weiss, R.D., 2005. Seeking Safety plus Exposure Therapy: an outcome study on dual diagnosis men. J. Psychoactive Drugs $37,425-435$.

Najavits, L.M., Weiss, R.D., Shaw, S.R., Muenz, L.R., 1998. “Seeking safety”: outcome of a new cognitive-behavioral psychotherapy for women with posttraumatic stress disorder and substance dependence. J. Trauma Stress 11, 437456.

National Center for PTSD and Walter Reed Army Medical Center, 2004. Iraq War Clinician Guide.

Norman, S.B., Tate, S.R., Wilkins, K.C., Cummins, K., Brown, S.A., 2010. Posttraumatic stress disorder's role in integrated substance dependence and depression treatment outcomes. J. Subst. Abuse Treat. 38, 346-355.

Northeastern Program Evaluation Center, 2007. Table of Program Types, http://vaww.nepec.mentalhealth.med.va.gov/PTSD/description.htm (accessed 5.25.2010).

Ouimette, P.C., Ahrens, C., Moos, R.H., Finney, J.W., 1998a. During treatment changes in substance abuse patients with posttraumatic stress disorder. The influence of specific interventions and program environments. J. Subst. Abuse Treat. 15, 555-564.

Ouimette, P.C., Ahrens, C., Moos, R.H., Finney, J.W., 1997. Posttraumatic stress disorder in substance abuse patients: relationship to 1-year posttreatment outcomes. Psychol. Addict. Behav. 11, 34-47.

Ouimette, P.C., Brown, P.J., Najavits, L.M., 1998b. Course and treatment of patients with both substance use and posttraumatic stress disorders. Addict. Behav. 23, 785-795.

Reger, M.A., Gahm, G.A., Swanson, R.D., Duma, S.J., 2009. Association between number of deployments to Iraq and mental health screening outcomes in US Army soldiers. J. Clin. Psychiatry 70, 1266-1272.

Regier, D.A., Farmer, M.E., Rae, D.S., Locke, B.Z., Keith, S.J., Judd, L.L., Goodwin, F.K., 1990. Comorbidity of mental disorders with alcohol and other drug abuse. results from the Epidemiologic Catchment Area (ECA) study. JAMA 264, 2511-2518.

Riddle, J.R., Smith, T.C., Smith, B., Corbeil, T.E., Engel, C.C., Wells, T.S., Hoge, C.W., Adkins, J., Zamorski, M., Blazer, D., 2007. Millennium cohort: the 2001-2003 baseline prevalence of mental disorders in the U.S. military. J. Clin. Epidemiol. 60, 192-201.

Rona, R.J., Hyams, K.C., Wessely, S., 2005. Screening for psychological illness in military personnel. JAMA 293, 1257-1260.

Roszell, D.K., McFall, M.E., Malas, K.L., 1991. Frequency of symptoms and concurrent psychiatric disorder in Vietnam veterans with chronic PTSD. Hosp. Commun. Psychiatry 42, 293-296.
Ruzek, J.I., 2002. Concurrent posttraumatic stress disorder and substance use disorder among veterans: evidence and treatment issues. In: Ouimette, P., Brown, P. (Eds.), Trauma and Substance Abuse: Causes, Consequences, and Treatment of Comorbid Disorders. American Psychological Association Press, Washington, DC, pp. 191-207.

Santiago, P.N., Wilk, J.E., Milliken, C.S., Castro, C.A., Engel, C.C., Hoge, C.W., 2010. Screening for alcohol misuse and alcohol-related behaviors among combat veterans. Psychiatr. Serv. 61, 575-581.

SAS Institute Inc., 2004. SAS. SAS Institute Inc., Cary, NC.

Seal, K.H., Bertenthal, D., Miner, C., Sen, S., Marmar, C., 2007. Bringing the war back home: mental health disorders among 103,788 US veterans returning from Iraq and Afghanistan seen at Department of Veterans Affairs facilities. Arch. Int. Med. $167,476-482$.

Seal, K.H., Bertenthal, D., Maguen, S., Gima, K., Chu, A., Marmar, C.R., 2008. Getting beyond “Don't ask; don't tell": an evaluation of US Veterans Administration postdeployment mental health screening of veterans returning from Iraq and Afghanistan. Am. J. Public Health 98, 714-720.

Seal, K.H., Metzler, T.J., Gima, K.S., Bertenthal, D., Maguen, S., Marmar, C.R., 2009. Trends and risk factors for mental health diagnoses among Iraq and Afghanistan veterans using Department of Veterans Affairs health care, 2002-2008. Am. J. Public Health 99, 1651-1658.

Sierles, F.S., Chen, J.J., McFarland, R.E., Taylor, M.A., 1983. Posttraumatic stress disorder and concurrent psychiatric illness: a preliminary report. Am. J. Psychiatry 140, 1177-1179.

Sinha, R., 2009. Modeling stress and drug craving in the laboratory: implications for addiction treatment development. Addict. Biol. 14, 84-98.

StataCorp, L.P., 2009. Stata Statistical Software: Release 11. StataCorp LP, College Station, TX.

Tanielian, T.L., Jaycox, L.H. (Eds.), 2008. Invisible Wounds of War: Psychological and Cognitive Injuries, their Consequences and Services to Assist Recovery. RAND Corporation, Santa Monica, CA.

Watkins, K.E., Burnam, A., Kung, F.Y., Paddock, S., 2001. A national survey of care for persons with co-occurring mental and substance use disorders. Psychiatr. Serv. 52, 1062-1068.

Wells, T.S., LeardMann, C.A., Fortuna, S.O., Smith, B., Smith, T.C., Ryan, M.A., Boyko, E.J., Blazer, D., 2010. A prospective study of depression following combat deployment in support of the wars in Iraq and Afghanistan. Am. J. Public Health 100, 90-99.

Wilk, J.E., Bliese, P.D., Kim, P.Y., Thomas, J.L., McGurk, D., Hoge, C.W., 2010. Relationship of combat experiences to alcohol misuse among U.S. soldiers returning from the Iraq war. Drug Alcohol Depend. 108, 115-121.

Wu, P.C., Lang, C., Hasson, N.K., Linder, S.H., Clark, D.J., 2010. Opioid use in young veterans. J. Opioid. Manag. 6, 133-139. 